\title{
scripted
}

Volume 14, Issue 1, June 2017

\section{Book review: Research Handbook on Digital Transformations}

\author{
F. Xavier Olleros and Majlinda Zhegu (Editors) \\ Cheltenham: Edward Elgar Publishing, 2016. 461 pages. \\ ISBN: $9781784717759 . £ 150$. \\ Reviewed by Joseph Savirimuthu* \\ (ㄷ) (ㄱ) $\odot$ \\ (C) 2017 Joseph Savirimuthu \\ Licensed under a Creative Commons Attribution-NonCommercial- \\ NoDerivatives 4.0 International (CC BY-NC-ND 4.0) license
}

DOI: $10.2966 /$ scrip. 140117.145

* Senior Lecturer in Law, School of Law and Social Justice, University of Liverpool 
How might future generations view the Internet and other innovations transforming society and its institutions at a scale and pace that has no historical precedent? Answering this question would have been challenging at the best of times, and it is now more difficult particularly as one of the Internet's inventors, Sir Tim Berners-Lee, has recently expressed some misgivings about the trajectory of normative underpinnings of innovation and the gradual colonisation by global technological elites of social and cultural domains. ${ }^{1}$

Research Handbook on Digital Transformations may, however, not be a bad place to start for thinking about information technology phenomena and how they can be harnessed to serve the wider interests of society. ${ }^{2}$ It is less crystal ballgazing and more focussed on setting out the descriptive, instrumental and normative aspects of the digital transformation economy, otherwise popularly known as the "DX economy." In Research Handbook on Digital Transformations, Olleros and Zhegu bring together 20 eminent scholars who offer their perspectives on a range of topics intended for a wide readership: researchers, policymakers in the public and private sectors, as well as not-for-profit organisations, legislators and students. The topics commissioned comprise an eclectic mix of the familiar (e.g. health, medicine, 3D printing and "local makerspaces", cloud computing contracts and smart cities) to those areas which merit serious consideration (e.g. education and the entrepreneurial university and legal academy, "Thingiverse"). There is also a chapter that reflects on

1 Tim Berners-Lee, “Tim Berners-Lee: I Invented the Web. Here are Three Things We Need to Change to Save It" (The Guardian, 12 March 2017), available at https://www.theguardian.com/technology/2017/mar/11/tim-berners-lee-web-inventor-saveinternet (accessed 1 June 2017).

2 Mark Weiser, "The Computer for the 21st Century" (1991) 265(3) Scientific American 94-104. 
something that transcends the digital. ${ }^{3}$ As the editors observe in their Introduction:

Some of today's youth probably wonder how previous generations managed to find suitable mates without the help of accessible, affordable and addictive online-dating platforms. They might also be shocked to learn that a few years back, online dating was still widely seen as a last resort for people who could not get a date in the 'real world'. (p. 11)

This can be regarded as one of many inspired choices by the editors when commissioning the contributions, since it also alerts us to the transformations taking place everywhere and impacting society and sectors differently:

Since digitization is and will remain a moving target for the foreseeable future, analysts will always work under the uneasy impression that if they were to delay publication for a few weeks, they would end up writing a very different text. Even so, we believe that there has never been a better time to assemble and publish a research handbook on digital transformations. Five years ago, some of the most intriguing initiatives underway - for example, drones and other autonomous vehicles, virtual and augmented reality, Bitcoin's blockchain, Thingiverse and Kickstarter - were widely dismissed as being of dubious merit. And five years hence, the scope and diversity of digital transformations will be such that a

3 Andreas Schmitz and Doreen Zillmann, “Online Dating Platforms: A Tool for Social Science Research" in F. Xavier Olleros and Majlinda Zhegu (eds.), Research Handbook on Digital Transformations (Cheltenham: Edward Elgar Publishing, 2016), pp. 160-181. 
single volume could hardly do them justice. Many social scientists have welcomed the opportunity to study a vast array of institutional transformations driven by the extensive deployment of digital technologies, from health and education to urban life, and from homes and libraries to games and crimes. (p. 9)

This review will not single out any particular contribution - not least for the reason that the various perspectives offer readers a rich kaleidoscope of the sociotechnical imaginaries revolving around mediated experiences with information. For those who are new to the range of issues raised by technological innovations and the Internet, the collection of essays provides a useful entry point into the inter-disciplinary dimensions of society in the digital age. The chapters are well-written and well-researched - the issues, contexts, opportunities and tensions are appropriately set out and analysed. Researchers and policymakers will be provided with a valuable resource seeking to explore the complexities of the sociotechnical milieu. The editors' choice of topics is probably informed by a desire to encourage its readership to take up some of the provocations and challenges raised by the authors:

Despite its wide and interdisciplinary assortment of contributions, a common message emerges from this book: the urgent need to rethink, recalibrate and perhaps reinvent our organizations, institutions, policies and cultures, so that they may better allow us to thrive in a world populated by growing numbers of intelligent machines.

With this work, we cannot pretend to have done more than scratch the surface of a broad and rich set of topics. But we hope that our tentative efforts will help other researchers to further explore some 
of the issues and discussions that we have here reported on. We also trust that entrepreneurs, policy makers and other stakeholders will find these academic exchanges useful in framing their own thinking and actions toward a better society, one as fit for humans as for their ever-more-intelligent machines. (p. 15)

A recurring cross-cutting theme from the contributions is how we frame policy challenges and issues for our institutions, regulations and lifeworlds will depend much on our capacity to re-imagine a just and democratic future as well as maintaining an eye towards the harsh realities of politics and the emerging environment of global tech elites. Each contribution makes an effort to confront well-known conceptual, social, economic and legal boundaries that are being redefined by digitalisation. This said, more could have been done here to situate digital transformations within some notable categories - "embodiment", "information markets", "re-intermediation of buyers and sellers", "data-driven operations", "commodification and colonisation of lifeworlds". The excitement that first greeted the invention of the Internet, and promissory note of democratisation of infrastructures for access and knowledge, would now seem to be more circumspect. The contributions offer some glimpses of these imaginaries; the pace and impact of the transformations are varied and impact is sectoral.

Each of the 20 chapters offers rich resources and ideas - but my thoughts could not help returning to a word used in the early part of the editors' introduction:

More than sixty years into the gradual but relentless digitization of our societies, we need to step back and carefully assess the historic [my emphasis] changes that are afoot. The recent shift from isolated 
programmable machines to connected and ubiquitous learning machines has raised the stakes and intensified the urgent need for enlightened analyses and choices. No social science on its own is sufficiently eclectic and encompassing for this task, but all of them in concert can begin to generate a better understanding of the challenges and opportunities that we face. (p. 9)

One of the most intriguing aspects of these contributions is the process by which digitalisation is transposing market logic and processes into other sectors - finance, innovation, business, law, education and social relations. It would have been beneficial to read a historian's perspective, which would have offered a nuanced view of the narratives revolving around the rhetoric of "innovation" and the role of "information" as fictitious commodities and the gradual commodification of lifeworlds. It is interesting to note the editors' reference Shoshana Zuboff's 2001 work ${ }^{4}$ but her more recent scholarship, seems to suggest that it is not evident that the digital transformation will be able to disentangle itself from the legacy of capitalist processes since:

...the currently institutionalizing logic of accumulation that produces hyperscale assemblages of objective and subjective data about individuals and their habitats for the purposes of knowing, controlling, and modifying behavior to produce new varieties of commodification, monetization, and control. ${ }^{5}$

4 Shoshana Zuboff, "Automate/informate: The Two Faces of Intelligent Technology" (2001) 14(2) Organizational Dynamics 5-18.

5 Shoshana Zuboff, "Big Other: Surveillance Capitalism and the Prospects of an Information Civilization" (2015) 30(1) Journal of Information Technology 75-89, p. 85. 
A historian, when looking at Snapchat's recent IPO valuation, would have noted that far too often, with increasing innovations and successes, our political institutions and market institutions feign to provide appropriate checks and balances, notwithstanding the growing citizenry mistrust of our digital overlords. Research Handbook on Digital Transformations may be an interlude to an all-too familiar historical tale - is transformation the solution or the problem? 